\title{
A NATUREZA DARWINISTA EM THOMAS HARDY
}

\author{
THE DARWINIAN NATURE IN THOMAS HARDY
}

Sophia Celina Diesel ${ }^{1}$

\begin{abstract}
RESUMO: O romancista e poeta inglês Thomas Hardy compartilha muitas questões e dúvidas apresentadas por seu contemporâneo naturalista Charles Darwin na famosa obra A Origem das Espécies. Discussões envolvendo a existência de Deus, o início da vida e o papel do homem no contexto natural (e social) provocadas pelo argumento de Darwin tornaram-se comuns na Inglaterra da segunda metade do século dezenove e surgem também na obra de Hardy. Ambos os autores foram acusados de heresia e de promover a imoralidade de um mundo sem Deus. Porém, uma análise mais cuidadosa aponta que para nenhum deles o fato de descer o homem da posição de obra central da criação significa o fim do sentido da vida; mas, pelo contrário, apenas que a natureza oferece uma nova espécie de moralidade.
\end{abstract}

PALAVRAS-CHAVE: Thomas Hardy; Charles Darwin; literatura vitoriana; ciências naturais.

ABSTRACT: The English novelist and poet Thomas Hardy shares many questionings and doubts presented by his contemporary, the naturalist Charles Darwin in his famous work On the Origin of Species. Discussions involving the existence of God, the beginning of life, and the role of man in the natural (and social) context provoked by Darwin's argument were common in England in the second half of the nineteenth-century and also appear in the work of Hardy. Both authors were accused of heresy and of promoting the immorality of a world without God. However, a closer look points that for neither of them the fact of descending man from the position of central feature of creation means the end of the meaning of life; but, on the contrary, simply that nature offers a new kind of morality.

KEYWORDS: Thomas Hardy; Charles Darwin; Victorian literature; natural science.

Thomas Hardy era um homem de personalidade reservada e gostos simples, cuja obra muitas vezes encontrava-se envolta em polêmicas devido ao que a crítica vitoriana tinha como seus muitos e agressivos ataques à igreja. A forma como a religião é representada em Hardy embora o autor negasse a agressividade - fora profundamente influenciada pela perda de sua fé nos dogmas cristãos, tanto pelas distorções de valores que ele via na igreja, quanto pelos novos rumos traçados pela ciência e a filosofia na segunda metade do século XIX. Em sua primeira biografia, creditada à sua segunda esposa, Florence Hardy, ele declara-se um dos

\footnotetext{
${ }^{1}$ Doutoranda em Estudos de Literatura pelo Programa de Pós-graduação em Letras da Universidade Federal do Rio Grande do Sul.
} 
primeiros proclamadores de A Origem das Espécies (1994, parte 1, p. 198) ${ }^{2}$ de Charles Darwin e, juntamente com George Eliot, é comumente citado entre os escritores vitorianos em cujas obras mais se percebe o interesse pelas ciências naturais e por exercitá-las na ficção. Reconhecidamente um observador do comportamento humano, Hardy ponderou sobre o papel do ser humano em relação às outras formas de vida e sobre o entendimento do contexto natural que se modificava muito em sua época, contradizendo e se distanciando do velho criacionismo e da moralidade religiosa que fundamentaram a organização social inglesa.

O impacto causado pela teoria evolucionista de Darwin deu-se principalmente pelo fato de o homem descer do pedestal de obra central da criação, e ser colocado em um patamar equivalente ao de outros seres vivos, como um entre os muitos elementos responsáveis pelo equilíbrio da natureza, onde o que determina a sobrevivência é a lei do mais adaptável e não a preferência divina. Ao proclamar a teoria darwinista, Hardy desafiou a moral religiosa, apresentando aos seus leitores um mundo amoral, onde as consequências de nossos atos não são definidas por merecimento; onde acontecimentos (bons ou maus) não são veículos para lições. Em decorrência disso, as jornadas de seus personagens não seguem o padrão tão difundido na literatura inglesa e que persistia na literatura vitoriana na qual a existência de Deus funcionava como a força superior que cedo ou tarde consertava o que estava errado e reestabelecia o equilíbrio moral no final da estória, recompensando os bons e punindo os maus. Porém, conforme Darwin, são diferentes os fatores que determinam o equilíbrio natural; são os mais fortes sobrevivem, não os moralmente superiores; o que coloca em dúvida o sentido de uma rígida doutrina religiosa em um mundo onde Deus deixa de ser uma certeza; onde as exigências e cobranças ligadas à religião geram mais sofrimento e frustração do que incentivam atos de bondade e companheirismo. Seguindo esse pensamento, em Tess of the D'Urbervilles (1891), Hardy expõe o sofrimento da protagonista, a jovem Tess, permanentemente punida por sua imoralidade (o estupro que sofre), nunca absolvida pela sociedade onde vive, ou sequer tendo suas dores aliviadas, pois não existe força maior para reverter a injustiça. Em Jude the Obscure (1895), o desolado Jude espera que alguém apareça para consolá-lo e incentivá-lo, mas ninguém vem, porque, conforme o narrador avisa, ninguém nunca vem; e assim o menino acaba desejando não fazer mais parte desse mundo (HARDY, 2004, p. 67). Ambos os protagonistas, apesar de bondosos e perseverantes, sucumbem diante do que é, no caso de Tess, o não cumprimento do código moral; e de Jude, a

\footnotetext{
${ }^{2}$ A edição comporta os dois volumes originais The Early Life of Thomas Hardy (London: Macmillan, 1928) e The Later Years of Thomas Hardy (London: Macmillan, 1930) indicados respectivamente como partes 1 e 2.
} 
teimosia de tentar alcançar mais longe do que sua classe permite. Tais expectativas irreais expõem, aos olhos do autor, o grande problema da idealização divina.

Hardy discute em seus romances a incompatibilidade entre a natureza humana, redescoberta dentro do contexto natural, e as exigências impostas pelo contexto social baseadas em dogmas desvirtuados; a dificuldade de dessacralizar o ser humano e enxergá-lo como parte de um contexto maior e mais complexo, sujeito a leis que ele não pode controlar ou muitas vezes sequer compreender, e, principalmente, que não existem para a sua satisfação.

\section{Charles Darwin}

Em seu famoso ensaio de 1859 A Origem das Espécies, Charles Darwin organiza, dá sentido e voz aos mais recentes avanços científicos nas áreas da biologia, botânica e geologia que borbulhavam na Inglaterra na primeira metade do século XIX. Por meio de analogias e linguagem acessível ele explica como as formas de vida que habitam o planeta não foram criadas simultânea e individualmente, e como não permanecem imutáveis ao longo do tempo, mas que são fruto de um perpétuo e árduo processo evolutivo, iniciado a partir de uma única forma de vida que ao longo do tempo deu origem a outras formas de vida e que, sempre através de multiplicação e variação, povoaram o mundo com a incrível diversidade que há nele hoje. Uma parte crucial do argumento é o funcionamento do mecanismo nomeado seleção natural, que seleciona os indivíduos mais fortes e adaptáveis entre os inúmeros que nascem para que procriem e perpetuem as espécies. Darwin explica que o processo evolutivo não só levou milhões de anos para chegar ao tempo presente como também é infinito e imprevisível. Evolução significa a permanente busca pelo equilíbrio natural, pela adaptação ao meio em constante mudança, onde todos os seres vivos lutam diariamente por sua sobrevivência, onde a espécie que não se adapta é extinta e substituída por outra mais apta; onde o indivíduo está sempre em desvantagem em relação ao meio; onde a morte está presente em toda a parte na manutenção da vida (DARWIN, 2008).

Antes de $A$ Origem, e durante ainda muito tempo após sua publicação, ciência e religião permaneciam intimamente conectadas. Porém, com o avanço da ciência, tornava-se cada vez mais difícil ignorar o fato de que a criação do mundo não era algo tão simples quanto afirmava a teoria criacionista (BEER, 2009, p. 10-11). Mesmo assim a desassociação das duas áreas era complicada, uma vez que a ciência ainda era tida como um veículo para evidenciar um cosmos onde tudo fazia sentido manifestando inteligência e intenção divina. 
Essa visão conhecida como teologia natural permaneceu popular até a primeira metade do século XIX, e obras famosas como Natural Theology de William Paley de 1802 serviram não só como ponto de partida ideológico para a ciência desvinculada da religião, mas também como a base linguística necessária para descrever interações e processos naturais nunca antes descritos e que viriam a ser popularizados por Darwin (BEER, 2009, p. 36).

O que instigava o jovem Darwin era a incompatibilidade que ele percebia entre o mundo que lia a respeito e o que via ao seu redor. Para ele, isso era fruto da arrogância humana, que apontava o homem como o centro do universo onde todo o resto deveria ser submisso a ele. Por exemplo, William Whewell, em On Astronomy and General Physics Considered with Reference to Natural Theology, (1836), afirma que a duração dos dias e das noites era determinada para que se ajustassem à necessidade de sono do homem (DARWIN, 2004, p. 43). Para Darwin o conceito de adaptabilidade não poderia ser entendido como uma via de mão única onde todos os elementos animados e inanimados viriam ao encontro das necessidades humanas. Tornou-se claro para ele durante seus estudos para a publicação de $A$ Origem que todos os seres dependem uns dos outros e precisam constantemente buscar a adaptação ao meio onde vivem; essa era a única forma de manter o equilíbrio natural (LEVINE, 1991, p. 24-26).

Darwin foi corajoso ao apresentar um mundo cujos mecanismos funcionavam independentemente de vontade ou do controle de um plano divino endossado por uma sociedade na qual a igreja e o clero não só eram os responsáveis pelas maiores instituições de ensino, mas também eram os grandes influenciadores do parlamento e da imprensa (WILSON, 2003, p. 227). Mais do que alterar a forma como a ciência passou a ser feita, Darwin provocou mudanças muito além da área científica, dali em diante. Polêmicas envolvendo o fenômeno da teoria darwinista iam de acusações de heresia a processos legais de promoção da promiscuidade e até pornografia (DAWSON, 2010, p. 3-4). Darwin (e seus apoiadores como o naturalista Thomas H. Huxley) teve de lidar com as muitas implicações de um texto (e contexto) que dava margem para diferentes interpretações e que mexiam com os mais profundos entendimentos da identidade humana. Todos, independentemente de terem lido A Origem das Espécies ou não, passaram a viver em um mundo darwinista, tamanho foi o alcance de suas ideias. George Levine, em Darwin and the Novelists (1991, p. 106), destaca que a propagação da teoria evolucionista deixou de restringir-se aos seus leitores; o darwinismo tornara-se popular demais para ser contido, e as possibilidades implícitas nele passaram a ser um elemento extremamente poderoso e polêmico na imaginação cultural. 


\section{Thomas Hardy e Darwin}

Thomas Hardy também precisou lidar durante toda a sua carreira com interpretações distorcidas da sua obra. Conhecido como um autor pessimista e fatalista, ele negava tal condição, pois tais rótulos lhe pareciam gratuitos, fruto de leituras superficiais, que pouco se importavam em justificar o dito pessimismo. Ele se irritava profundamente com a insistência da crítica em atribuir-lhe as mesmas convicções ou incongruências de seus personagens e de propagá-los com intuito sensacionalista, sendo que ele sempre que possível rebatia as críticas afirmando não criar retratos definitivos do ser humano, mas sim impressões (HARDY, 1984, p. 406). Como um verdadeiro proclamador da visão de Darwin, Hardy não acreditava em explicações simples, em soluções fáceis; também como o naturalista, não acreditava em evolução como sinônimo de progresso, mas de eterna busca por equilíbrio.

Como muitos intelectuais no fim do século, Hardy se interessou pelos mecanismos da seleção natural para tentar entender o mundo, a vida em sociedade e talvez, mais do que isso, como conforto para sua mente inquieta. Por exemplo, chamou a atenção dele como o aumento descontrolado da população podia ferir o princípio evolutivo e desequilibrar a harmonia natural (CAREY, 1992, p. 10 e 24). O filósofo Herbert Spencer (1969, p. 82-84), reconhecido por transpor a teoria evolucionista do mundo biológico para o mundo social, e extremamente popular entre os intelectuais da época, apontava em 1884 a forma equivocada como a raça humana tendia a dar suporte aos mais fracos (entenda-se geralmente aos mais pobres), impossibilitando assim o trabalho da seleção natural sobre o ser humano. Ele criticava a ação dos governos que não permitiam que as pessoas, principalmente nas grandes cidades, lutassem pela própria sobrevivência; e que tiravam recursos de uns para dar a outros que, se deixados por si sós, não seriam capazes de se sustentar. Essas questões influenciaram o pensamento intelectual do final do século XIX, incluindo seus principais artistas e escritores, aflitos com a ascensão das massas. Em 1888, Hardy escreveu em seu diário sobre "a taxação aos que produzem para ajudar as massas da população que não se ajudarão mesmo quando puderem. As oportunidades deveriam ser iguais para todos, mas aqueles que não são capazes de aproveitá-las deveriam receber apenas o mínimo para não se tornarem um fardo ou os senhores daqueles que são capazes.” (HARDY, 1994, parte 1, p. 268) ${ }^{3}$ Outro pensamento recorrente era que as massas eram compostas de seres imbecilizados, intelectualmente

\footnotetext{
${ }^{3}$ Minha tradução para: "[T]he taxing of the worthy to help those masses of the population who will not help themselves when they might, etc. Opportunity should be equal for all, but those who will not avail themselves of it should be cared for merely- not be a burden to, nor the rulers over, those who do avail themselves thereof."
} 
inferiores e desprovidos de individualidade. Para a elite artística da época, a popularização da educação desvalorizava a arte, tornando popularidade sinônimo de mediocridade; então, artistas como George Gissing ou Henry James, mesmo prejudicados nas vendas de seus livros, orgulhosamente abstraiam-se do grande público, negando-se a escrever uma literatura considerada "fácil". 4

Hardy nunca se mostrou radical em relação às massas; preferia manter-se discreto. Mesmo assim, em seu diário é possível perceber que ele não se sentia confortável com multidões; sua busca pelo isolamento do campo e a preocupação em nunca permanecer muito tempo em Londres demonstram isso. Novamente em seu diário ele escreveu, em 1887: "Podese dizer que uma multidão contém uma pequena minoria que possuem almas sensíveis; esses, e o aspecto desses, são os que vale a pena observar. Então temos a multidão dividida entre os estúpidos, os inconscientes, os sem alma; e os vivos, pulsantes, sofredores, vivazes. Em outras palavras, almas e máquinas, éter e barro" (HARDY, 1994, parte 1, p. 243). ${ }^{5}$ Partindo do princípio que a dominação humana sobre os outros animais acontece devido à qualidade intelectual humana, o excesso de população representaria a quantidade sobre a qualidade, maior exigência de recursos do planeta e até um eventual retorno à barbárie, como enfatiza John Carey (1992, p. 13), em contraste com a sociedade intelectualmente sofisticada da qual a elite artística se via como representante.

Se a dominação humana, mesmo controversa, era inegável, no entendimento evolucionista ela não poderia ser, porém, fruto de preferência divina. Como explicá-la, então? Hardy acreditava na possibilidade de o homem simplesmente ter evoluído demais, aproveitando-se de suas vantagens intelectuais, e assim subjugando as demais espécies. Mas seria a (N)atureza responsável (ou culpada) por essa evolução exagerada? Ele escreveu em 1889:

Um fato lastimável - a raça humana é desenvolvida demais para suas condições corporais, tendo os nervos evoluído a um nível anormal para tal ambiente [...]. Podemos questionar se a Natureza, ou o que chamamos Natureza, no passado, quando cruzou a linha entre os vertebrados e os invertebrados, não se excedeu em

\footnotetext{
${ }^{4}$ Em carta para o amigo Eduard Bertz, Gissing reclama que quando escrevia pensava em seus melhores leitores, não nas massas (GISSING, 1961, p. 196). Henry James disse a seu irmão William, em relação a crítica por seu estilo ser refinado demais, que tinha horror mortal de escrever "thin" (sem profundidade, superficialmente) e se esse era o gosto das multidões, então ele não teria medo de passar fome. (KAPLAN, 1999, p. 138).

${ }^{5}$ Minha tradução para: "You may regard a throng of people as containing a certain small minority who have sensitive souls; these, and the aspects of these, being what is worth observing. So you divide them into the mentally unquickened, mechanical, soulless; and the living, throbbing, suffering, vital. In other words, into souls and machines, ether and clay."
} 
sua missão. Este planeta não fornece as ferramentas necessárias para a felicidade de existências superiores (HARDY, 1994, parte 1, p. 285-286). ${ }^{6}$

Antes disso, em 1883 ele já havia dito que o ser humano atingira um nível de inteligência que a natureza não previra quando planejava suas leis e que consequentemente não tem com proporcionar satisfação adequada (HARDY, 1994, parte 1, p. 213). Em 1885:

Quanta hipocrisia: a Natureza é a maior das mentirosas. Engana as crianças por completo; e a parcela mais velha da sociedade mais ou menos, conforme com seu poder de introspecção; contudo, mesmo esses raramente compreendem que nada é o que parece ser (HARDY, 1994, parte 1, p. 231). ${ }^{7}$

Em trechos como esses, Hardy acaba cometendo a inconsistência de simplesmente substituir a palavra Deus por (N)atureza em seu questionamento. Consciente disso, ele admite que a atitude de basearmos nossa conduta na aparente conduta da natureza provará ser desastrosa para a humanidade (1984, p. 339). Para Beer (2009, p. 222), ao chamar a natureza de mentirosa Hardy compartilha com Darwin a sensação de que suas leis devem ser falhas, pois não são capazes de suportar a complexidade humana, criada por elas mesmas. Por outro lado, ao tentar atribuir intuito à natureza, ou adotá-la como veículo para a intenção de um Criador, a grande dúvida passa a ser a razão para que esse Criador onipotente não tenha controle sobre o próprio mundo; ou sequer proporcione as devidas condições para a vida plena de sua própria criação.

Era essa a questão mais problemática na teoria darwinista: abrir mão da necessidade de Deus e aceitar o acaso como responsável por tudo. Com essa premissa, o homem desperta para uma realidade onde ele perde o posto de ápice da criação e torna-se uma produção aleatória de uma lei inexorável, operando com qualquer material que encontre (INGHAM, 2003, p. 67). Porém, sua excessiva evolução o coloca novamente em uma posição central, superior às outras espécies e o enche de incertezas sobre suas responsabilidades morais em relação a elas e sobre si mesmo.

\section{Religião}

\footnotetext{
${ }^{6}$ Minha tradução para: "A woeful fact - that the human race is too extremely developed for its corporeal conditions, the nerves being evolved to an activity abnormal in such an environment. [...] It may be questioned if Nature, or what we call Nature, so far back as when she crossed the line from invertebrates to vertebrates, did not exceed her mission. This planet does not supply the materials for happiness to higher existences."

${ }^{7}$ MInha tradução para: "The Hypocrisy of things. Nature is an archdissembler. A child is deceived completely; the older members of society more or less according to their penetration; though even they seldom get to realize that nothing is as it appears."
} 
O cristianismo fez sempre parte da vida de Hardy. Mesmo vindo de uma família que não era extremamente religiosa, na infância ele costumava frequentar a igreja, ler a Bíblia, e até mesmo cogitou a possibilidade de seguir uma formação religiosa em Cambridge. Desistiu ao entender que isso limitaria sua liberdade intelectual, assim como Jude também percebe a certo ponto da história (TOMALIN, 2006, p. 54-55). Não se sabe quando exatamente Hardy teve seu primeiro contato com a obra de Darwin - a publicação de $A$ Origem data de quando ele tinha dezenove anos - mas tanto sua obra literária quanto suas reflexões em diários, cartas e eventuais discursos demonstram o quanto o pensamento evolucionista the provocava reflexão. Desde suas primeiras publicações ele levantava questões sobre a suposta superioridade humana pregada pelo cristianismo: se o homem seria uma exceção às leis da natureza e se havia uma razão especial para acreditar na existência de um Deus que se importava em especial com ele sendo que a natureza não parecia fazer essa distinção (BUTLER, 1980, p. 11). Assim como Darwin, ele desde cedo duvidou da arrogância do criacionismo e de explicações que afirmavam a existência de um mundo repleto de bondade e moralidade mas que, sob um olhar mais atento, exibia tanta dor e sofrimento. ${ }^{8}$ Ele não entendia como a existência do mal era permitida por uma divindade que facilmente podia derrotá-lo e proporcionar a todos um mundo melhor (HOLLAND, 1966, p. 125-126).

Conforme Tomalin (2006, p. 220), a crítica contemporânea a Hardy costumava ter dificuldades em identificar o tom evolucionista por trás do seu dito pessimismo. Já mais tarde, entre os que conseguiram fazê-lo está David Lodge, que viu em The Woodlanders a brutalidade da seleção natural na sobrevivência do frio Fitzpiers, em contrapartida com a morte do sensível Winterborne, deixando Grace nas garras do vilão. Winterborne é eliminado por ser parte da velha ordem rural Inglesa, fadada a sofrer as consequências da mudança dos tempos, enquanto que Fitspiers é fruto da nova ciência e, portanto, mais capaz de se adaptar à modernidade; sendo seu caráter moral aceitável ou não perante padrões tradicionais. Apesar de conhecido como a última voz da velha civilização rural, Hardy reconhecia a inevitabilidade do processo que destruía o velho trabalhador e os velhos hábitos do campo, e encarava isso como parte do processo evolutivo (WILLIAMS, 1973). Porém, a aparente falta de preocupação em dar sentido moral a tudo quebrava as expectativas do leitor e principalmente da crítica, que passou a taxá-lo como um autor trágico. A tragédia, porém, era para ele algo bem menos subversivo. Em seu diário em 1888, Hardy escreveu que quem olhasse além da

\footnotetext{
${ }^{8}$ Darwin confessa não poder persuadir-se que um Deus onipotente e bondoso criaria propositadamente ichneumonidae com a expressa intenção que eles devorem os corpos de centopeias vivas ou gatos que brincam com ratos. (DARWIN, 1896. p. 554-555).
} 
superfície de qualquer farsa, veria uma tragédia; e, ao contrário, quem se abstivesse das questões mais profundas de uma tragédia, veria uma farsa (HARDY, parte 1, p. 282). O trágico, ele pensava, assim como o sofrimento e a própria morte, age naturalmente sobre um ambiente evolucionista; o que não significa que o vazio deixado por Deus também não incomodasse o autor. Novamente em 1890 ele escreveu: "Procuro Deus há cinquenta anos, e acho que se ele existisse, eu já o teria descoberto. Como uma personalidade externa, é claro o único verdadeiro sentido do mundo". (HARDY, F., parte 1, p. 293) ${ }^{9}$

Os tão criticados ataques ao cristianismo nos romances de Hardy acontecem por conta das representações religiosas que fazem parte de sua formação, da época em que ele vivia, mesmo que já desacreditasse delas. São referências por vezes dúbias ao ironizarem a leitura distorcida e complicada dos fundamentos cristãos. Hardy não era contra a religiosidade em si, mas sim contra o egocentrismo humano e o esquecimento dos fundamentos simples que, segundo ele, no passado eram mais valorizados (SCHWEIK, 1999, p. 55-56). Seus personagens mais carismáticos são aqueles que dão valor às pequenas coisas da vida, à bondade e ao que torna a vida melhor durante sua breve existência, conforme a capacidade humana. Gabriel Oak (Far From the Madding Crowd) e Elizabeth-Jane (The Mayor of Casterbridge) são movidos por uma moralidade facilmente identificável como a moralidade cristã, de forma ética e simples: são generosos, honestos, prestativos. Hardy por vezes deu voz a um desejo de ver uma igreja reformada, uma igreja que promovesse uma existência virtuosa, em harmonia com todos os homens honestos, e que reverenciasse o amor por um ideal ético (HARDY, 1978, p. 136). Por isso, não surpreende o fato de ele nunca procurar um substituto para sua fé, mas sim que procurasse em seus livros enfatizar como a moral humana não pode ser reduzida a uma fórmula. Em romances como Tess, Jude e The Return of the Native ele demonstra como pode ser desastroso tentar fazer a substituição de uma fé incoerente por outra. Clym, Angel e Sue falham em buscar o sentido de suas vidas em crenças alternativas como a mistura helenico-pagã de Sue ou as riquezas de Clym em Paris (SCHWEIK, 1999, p. 58). Porém, se as referências à simplicidade e harmonia passam por vezes despercebidas em meio à tragédia Hardiana, as referências à fé mal praticada em compensação são gritantes, pois são elas que dão origem à tragédia e à infelicidade: Lady Constantine (Two on a Tower) sacrifica sua felicidade e nega seu amor pelo jovem Swithin em nome de uma sociedade intolerante à liberdade e à sexualidade feminina; Tess e Jude expõem a forma como o cristianismo acabara difundindo consequências malignas ao aprisionar as pessoas em regras

\footnotetext{
${ }^{9}$ Minha tradução para: "I have been looking for God 50 years, and I think that if he had existed I should have discovered him. As an external personality, of course - the only true meaning of the word."
} 
contraditórias. Angel abandona Tess quando descobre seu passado imoral, mesmo acreditando na inocência da amada, além de toda a própria conviç̧ão de possuir uma mente mais esclarecida e aberta do que seus irmãos párocos. Fé e moralidade ainda estão vinculadas demais nele, o que o deixa confuso. Em Jude, Sue enfim entrega-se à religiosidade obsessiva, contra todas as suas prévias convicções de liberdade intelectual, quando acredita estar sendo punida por sua rebeldia por uma força maior que não consegue compreender.

Os ataques por parte da crítica, principalmente a Tess e em seguida a Jude, irritaram Hardy a ponto de fazê-lo desistir de escrever outros romances. Ele passou então e se dedicar unicamente à poesia, sua maior paixão, mas mesmo assim sua imagem permaneceu ligada às polêmicas até o fim. O personagem de Eustacia Vye de The Return of the Native parece partilhar da sensação que Hardy tinha de não falar a mesma língua de seus contemporâneos, da agonia de não conseguir se fazer entender. De personalidade intensa e inconformada com a vida rústica de Egdon Heath, Eustacia tem uma mente avançada, original e desafiadora. Sua insatisfação em relação à rotina e à falta de emoção a faz frequentar pouco a igreja e ter hábitos reclusos. O resultado disso é que ela é tida por moradores da região como estranha, antissocial, até mesmo uma bruxa. No decorrer do romance Eustacia é desprezada por moradores locais e é inclusive vítima de um feitiço contra bruxarias. Para evitar mais condenações provocadas pela ignorância das pessoas, assim como Eustacia, seu criador preferiu se retirar e buscar paz na amada região de Wessex, onde morava com sua esposa Emma na isolada moradia de Max Gate.

\section{Natureza e moralidade}

A comunhão de Eustacia com a natureza não é espontânea. A garota preferiria morar em Paris ou em qualquer outro lugar mais civilizado do que Edgon Heath. Ao casar-se com Clym ela imaginava estar a um passo da liberdade, porém o desejo de seu marido se mostra exatamente contrário ao dela: ele pretende permanecer no campo e nunca mais voltar à cidade grande. Clym quer distância da corrupção da metrópole; da busca interminável por dinheiro e posição social; ele deseja encontrar a felicidade exatamente na simples comunhão com a natureza. Neste viés, Hardy se aproxima mais dele, o nativo retornado do título, em seu desejo pela simplicidade, pela paz e pela distância das futilidades do mundo moderno.

Em atitudes como a de Clym, Hardy expressa a verdadeira semelhança entre seus pensamentos e os de Darwin, mais autêntica do que as formas mais obviamente enfatizadas como competição, esforço pela sobrevivência, aleatoriedade e sofrimento inevitável. É natural 
apontar a presença de um pensamento evolucionista em imagens como a do ser fossilizado que encara Henry Knight no barranco em A Pair of Blue Eyes, ou nas árvores se debatendo em The Woodlanders, pois essas foram sempre as mais populares imagens darwinistas, por remeterem à briga direta pela sobrevivência e às provações que levam o mais forte à vitória (LEVINE, 2009, p. 36). Porém Wilson (2003, p. 230) aponta que, mais importante do que esses aspectos óbvios, há outro que se tornou culturalmente popular somente a partir do final do século XX: a importância da relação de interdependência das espécies de uma forma mais igualitária e menos baseada em exigências por parte do ser humano. Essa visão fez parte da teoria darwinista desde o início, mesmo que implicitamente, mas muito poucos estavam preparados para entendê-la.

Em uma era de religiosidade mais dispersa e que reconhece a importância da preservação do planeta como o século XXI, a visão de Darwin ganha nova amplitude e significado. Sua atenção para os pequenos detalhes, sua leitura instintiva dos elementos aparentemente estáticos em relação aos não estáticos, e sua busca por sentido foram os grandes fatores que mesmo pouco percebidos na época despertaram o interesse de Hardy. Os dois autores se identificam em seu mútuo amor, na meticulosa e eticamente intensa atenção a tudo que a natureza engloba, orgânico ou inorgânico, e nas narrativas latentes em todas as coisas (LEVINE, 2009, p. 37-38). É através dessa faceta mais simples e menos sensacionalista da teoria de Darwin que Hardy demonstra sua atenção às pequenas coisas e à beleza dos detalhes: no ruído produzido pela chuva, nas diferentes espécies de plantas, nas cores do céu. É em tais momentos de simplicidade que, conforme Virginia Woolf (1986, p. 238), reconhecemos o Thomas Hardy observador da natureza, o pintor de paisagens, que faz com que o leitor se sinta parte daquele lugar, apegue-se a ele, mesmo que isso signifique partilhar também da percepção de sua insignificância em relação ao mundo em geral. Como no início de Far From the Madding Crowd (1874) onde ele escreve: "a fina grama, mais ou menos cobrindo a colina, era tocada pelo vento em brisas de variadas intensidades - umas raspando as folhas severamente, outra as enfileirando intensamente, e outra as penteando como uma escova macia" (HARDY, T., 2010, p. 7). ${ }^{10}$ Passagens como essa e muitas outras não interferem diretamente no desdobramento da trama, não são dramáticas ou trágicas, mas fazem a diferença na sutil construção que o leitor faz do ambiente e da importância dele para os que ali vivem e dele dependem.

\footnotetext{
${ }^{10}$ Minha tradução para: "The thin grasses, more or less coating the hill, were touched by the wind in breezes of differing powers, and almost of differing natures — one rubbing the blades heavily, another raking them piercingly, another brushing them like a soft broom."
} 
Assim Levine (2003, p. 38) argumenta que o mundo de Hardy não é afinal tão desolador quanto parece à primeira vista; que o sentido da existência humana não se perdeu depois da perda da fé; mas sim que os valores éticos e morais se modificaram. Apesar de explorar o lado sombrio da teoria darwinista, a aceitação da morte ou do sofrimento, a natureza em Hardy também é capaz de inspirar afeto, um sentimento de pertencimento e a possibilidade de plenitude de forma diferente, mas igualmente edificante. Seus personagens dependem da terra, do que é produzido por ela; dependem uns dos outros em um ciclo constante de convivência, assim como os indivíduos de Darwin. São poucos os autores vitorianos que invocam esse sentimento tão rico da natureza viva, em movimento, energizante. Em Two on a Tower (1882) a descoberta da vastidão do espaço por Lady Constantine e Swithin os faz sentir pequenos e ao mesmo tempo lhes dá a sensação de liberdade negada em sociedade de se amarem livremente. Em comparação com o espaço, as mesquinharias mundanas que tanto os consomem perdem a importância; a natureza os liberta em todos os sentidos. Tess percebe claramente esse conflito entre a moralidade artificial e a moralidade natural quando se vê na floresta, sozinha, à noite. Lá ela não se sente só, mas livre; lá o problema de estar viva reduz-se às menores proporções; sua maior vontade é poder evitar a humanidade de vez, tão terrível como um todo, mas tão débil e insignificante em seus membros. O narrador continua:

\begin{abstract}
Nessas solitárias colinas e vales seu tranquilo caminhar era parte integrante do elemento no qual ela se movimentava. Sua furtiva e sinuosa figura tornava-se parte da cena. Por vezes sua caprichosa imaginação intensificava os movimentos naturais ao seu redor até eles parecerem parte de sua própria história. Felizmente eles se tornavam parte de sua história, pois o mundo nada mais é do que um fenômeno psicológico, e aquilo que os elementos parecem, eles são. As brisas e os ventos da meia noite, lamentando-se por entre os brotos das plantas e as cascas dos galhos secos eram um diagrama da amarga reprovação. Um dia úmido era a expressão da irremediável dor causada por sua fraqueza na mente de algum impreciso ser ético o qual ela não conseguia classificar definidamente como o Deus de sua infância, e também não conseguia compreender como nenhum outro. Mas essa abrangência de sua própria caracterização, baseada em retalhos de convenções, povoada por fantasmas e vozes antipáticas a ela, era uma triste e equivocada criação da imaginação de Tess - uma nuvem de duendes morais com os quais ela estava aterrorizada sem razão. Eles é que estavam em desarmonia com o mundo real, não ela. Ao caminhar em meio aos pássaros adormecidos nos arbustos, ao observar os coelhos saltando para dentro e fora das tocas, ou parados embaixo de um galho carregado de faisões, ela olhou para si própria como a efígie da Culpa invadindo o refúgio da inocência. Mas durante todo o tempo estimava uma diferença que não tinha importância. Por sentir-se em antagonismo, ela estava perfeitamente em harmonia. Ela fora forçada a romper com uma reconhecida lei social, mas não via nenhuma lei conhecida pelo meio natural que a fizesse sentir-se tamanha anomalia (HARDY, 2013, p. 114-115). ${ }^{11}$
\end{abstract}

\footnotetext{
${ }^{11}$ Minha tradução para: "On these lonely hills and dales her quiescent glide was of a piece with the element she moved in. Her flexuous and stealthy figure became an integral part of the scene. At times her whimsical fancy
} 
A reprovação que Tess sente no vento batendo nos galhos secos representa o que ela foi ensinada que deve representar. Sua desgraça está presente em uma moralidade forçada, punitiva, baseada na forma como as pessoas são instruídas a ler a natureza, não na forma como elas a sentem individualmente. O Deus da infância de Tess não é nada além disso, um Deus rigoroso e punitivo que determina seu castigo até o fim da vida porque ela pecou contra o código social. Porém Tess não consegue deixar de pensar que algo está errado nessa representação. Com sensibilidade aliada a uma educação mais sofisticada do que as dos membros mais velhos de sua família e de grande parte de sua comunidade, ela possui uma perspectiva diferente e percebe que certas imposições podem não oferecer uma interpretação honesta do mundo, mas sim "baseada em retalhos de convenções e povoada de fantasmas antipáticos a ela”. Ela percebe então ali em suas reflexões na floresta que são essas leis que estão em desarmonia com o mundo natural e não ela própria.

Hardy estava convencido de que a imagem de um Deus punitivo desacordava com o mundo que ele percebia ao seu redor e que a ciência estava ajudando a desvendar. Ele provoca em seus romances a sensação de que apesar da aleatoriedade da sorte e das incertezas de um mundo regido pelo acaso, onde o sofrimento faz parte da vida, muito mais sofrimento há para aqueles que lutam contra as forças do mundo natural, que não as aceitam. Em A Origem, Darwin explica que ao refletirmos sobre a luta pela sobrevivência, podemos certamente nos consolar ao saber que medo não faz parte dela, que a morte é geralmente rápida, e que os mais vigorosos, saudáveis, e os mais felizes são os que sobrevivem e se multiplicam (DARWIN, 2008, p. 62). O intrigante termo felizes é interpretado por Levine como a vontade de sobreviver que move os seres vivos a lutar pela vida, o instinto de sobrevivência que pode fazer a luta valer a pena, mesmo que, no caso do racional ser humano, seja uma luta repleta de incertezas. (2009, p. 37). A consciência das dificuldades, da dor e da eminência da morte faz com que tudo seja mais complicado; porém, conforme o próprio Hardy, é inútil tentar

would intensify natural processes around her till they seemed a part of her own story. Rather they became a part of it; for the world is only a psychological phenomenon, and what they seemed they were. The midnight airs and gusts, moaning amongst the tightly-wrapped buds and bark of the winter twigs, were formulae of bitter reproach. A wet day was the expression of irremediable grief at her weakness in the mind of some vague ethical being whom she could not class definitely as the God of her childhood, and could not comprehend as any other. But this encompassment of her own characterization, based on shreds of convention, peopled by phantoms and voices antipathetic to her, was a sorry and mistaken creation of Tess's fancy - a cloud of moral hobgoblins by which she was terrified without reason. It was they that were out of harmony with the actual world, not she. Walking among the sleeping birds in the hedges, watching the skipping rabbits on a moonlit warren, or standing under a pheasant-laden bough, she looked upon herself as a figure of Guilt intruding into the haunts of Innocence. But all the while she was making a distinction where there was no difference. Feeling herself in antagonism, she was quite in accord. She had been made to break an accepted social law, but no law known to the environment in which she fancied herself such an anomaly." 
entender as intenções da natureza, uma vez que caso elas realmente existam isso seria indiferente para nós, já que tais leis não estariam ao alcance da nossa compreensão. Em uma crítica à obra Apology for Nature (1902) de Maeterlinck ele discorda da existência de uma natureza vingativa, e aponta para a insensatez de procurar um esquema moral nela que se encaixe nas expectativas humanas, servindo como justificativa para substituir Deus por um credo supostamente mais verdadeiro.

Sempre houve dor, e dor sempre haverá: nenhum tipo de moral atribuída à Natureza pode remover a dor do passado e transformá-la em prazer, nem mesmo para os seus mais infalíveis seguidores. E nenhuma injustiça, por menor que seja, pode ser recompensada por sua futura generosidade, mesmo que grandiosa, enquanto considerarmos que a Natureza seja, ou simbolize, o poder absoluto (HARDY, 1994, parte 2 , p. 97). ${ }^{12}$

Herbert Spencer (1969, p. 83) também defendia que o sofrimento não pode ser eliminado da existência humana e que artifícios sociais somente agravam a situação. A convicção do povo de que o sofrimento é alheio ao funcionamento normal da vida e que deveria ser completamente erradicado, como se isso fosse possível, é uma distorção de um dos enunciados básicos do Cristianismo que os próprios cristãos resistem em aceitar: que a criatura que não for capaz de se sustentar deve perecer. O resultado disso é a pressão sobre os governos por leis e ações que acabem com o sofrimento como as famosas leis dos pobres (Poor Laws) que além de absurdas, não somente impedem o avanço da humanidade, mas a fazem retroceder (SPENCER, 1969, p. 84-85).

Spencer também alerta para o perigo de escrever natureza com $\mathrm{N}$ maiúsculo (como Hardy faz) e que mais mal tem sido causado na história recente por aqueles que idolatram a natureza do que por muitos idólatras tradicionais e idealistas (1969, p. 36-37). Para Beer (2009, p. 36), o perigo de pensar em uma reorganização social supostamente baseada na natural com o intuito de buscar a felicidade da qual Darwin fala é que ela lembra aspectos da antiga teologia natural, onde a ordem de todas as coisas era necessariamente benigna, pois tudo existia conforme o desejo do Criador. Novamente corre-se o risco de cair na armadilha da ânsia de compreender o sentido da vida a qualquer custo, de encaixar seus mecanismos em padrões conhecidos e de buscar a compensação pela dor.

\footnotetext{
${ }^{12}$ Minha tradução para: "Pain has been, and pain is: no new sort of morals in Nature can remove pain from the past and make it pleasure for those who are its infallible estimators, the bearers thereof. And no injustice, however slight, can be atoned for by her future generosity, however ample, so long as we consider Nature to be, or to stand for, unlimited power."
} 
Mesmo convicto da autenticidade de seus estudos, Charles Darwin foi um precursor que sentiu na pele as grandes dificuldades em desvincular o mundo natural do Deus da teologia natural. Em vários trechos de $A$ Origem ele chega a incluir um "Criador" inutilmente posando por trás dos mecanismos naturais, trabalhando através de meios incompreensíveis, mais como uma tentativa de amenizar a crueza da seleção natural do que por crença. Porém seu próprio texto demonstra o quanto isso era desnecessário. Há um frequente movimento na prosa de Darwin, depois também na de Thomas Hardy, que sugere uma possível felicidade em meio a tanta profusão de luta e sofrimento, onde a busca por um sentido absoluto precisa dar lugar à percepção da beleza, da vastidão, da conformidade de que não se pode chegar a uma resposta final (BEER, 2009, p. 94-95). São essas oscilações que possibilitam leituras pessimistas e otimistas do mundo regido pelo acaso; que provocam a tensão entre felicidade e dor, e a sensação de um mundo natural ao mesmo tempo extraordinário e brutal, exuberante e sensível, que constantemente subverte qualquer classificação moral que se queira fazer dele.

\section{REFERÊNCIAS}

BEER, Gillian. Darwin's plots: evolutionary narrative in Darwin, George Eliot and nineteenth-century fiction. 3rd edition. Cambridge: Cambridge University Press, 2009. . Introduction. In: DARWIN, Charles. On the origin of species: by means of natural selection or the preservation of favored races in the struggle for life. Oxford: Oxford University Press, 2008. p. VII-XXV. BUTLER, Lance St. John. Thomas Hardy. Cambridge: Cambridge University Press, 1980. CAREY, John. The intellectuals and the masses: pride and prejudice among the literary intelligentsia, 1880 - 1939. London: Faber and Faber, 1992.

DARWIN, Charles. On the origin of species: by means of natural selection or the preservation of favoured races in the struggle for life. BEER, Gillian (Ed.). Oxford: Oxford University Press, 2008. 1896. . Life and letters of Charles Darwin. DARWIN, Francis (Ed.) New York: D. Appleton, The descent of man: and selection in relation to sex. London: Penguin, 2004. DAWSON, Gowan. Darwin, literature and Victorian respectability. Cambridge: Cambridge University Press, 2010. GISSING, George. The letters of George Gissing to Eduard Bertz, 1887-1903. YOUNG. Arthur C. (Ed.). New Brunswick: Rutgers University, 1961. HARDY, Florence. The life of Thomas Hardy. London: Studio Editions, 1994.

HARDY, Thomas. Jude the obscure. Plymouth: Broadview, 2004. . Far from the madding crowd. London: Harper Collins, 2010. . The collected letters of Thomas Hardy. PURDY, Richard Little; MILGATE, Michael (Eds.). Vol. 1. Oxford: Clarendon, 1978. 1984. . Life and works of Thomas Hardy. MILGATE, Michael (Ed.). London: Macmillan, HOLLAND, Clive. Thomas Hardy: the man, his works and the land of Wessex. New York: Haskell House, 1966. 
INGHAM, Patricia. Thomas Hardy. Oxford: Oxford University Press, 2003.

KAPLAN, Fred. Henry James: the imagination of genius. Baltimore: Johns Hopkins University, 1999.

LEVINE, George. Hardy and Darwin: an enchanting Hardy? In: WILSON, Keith (Ed.). A companion to Thomas Hardy. Oxford: Wiley-Blackwell, 2009. pp. 36-53.

. Darwin and the novelists: patterns of science in Victorian fiction. 2nd edition.

London: University of Chicago Press, 1991.

SCHWEIK, Robert. The influence of religion, science, and philosophy. In: KRAMER, Dale (Ed.). The Cambridge companion to Thomas Hardy. Cambridge: Cambridge University Press, 1999. p. 54-72.

SPENCER, Herbert. The man versus the State: four essays on politics and society. MACRAE, Donald (Ed.). London: Penguin, 1969.

TOMALIN, Claire. Thomas Hardy: the time-torn man. London: Viking, 2006.

WILLIAMS, Raymond. The country and the city. Oxford: Oxford University Press, 1973.

WILSON, A. N. The Victorians. London: Arrow, 2003.

WOOLF, Virginia. The second common reader: annotated edition. NEILLIE, Andrew (Ed.). London: Harvest, 1986.

Recebido em 24/07/2018. Aceito em 24/10/2018. 